\title{
Identifying the Main Factors of Iran's Economic Growth Using Growth Accounting Framework
}

\author{
Mohammadreza Mahmoudi
}

\section{ABSTRACT}

This paper aims to present empirical analysis of Iranian economic growth from 1950 to 2018 using data from the World Bank, Madison Data Bank, Statistical Center of Iran, and Central Bank of Iran. The results show that Gross Domestic Product (GDP) per capital increased by 2 percent annually during this time, however this indicator has had a huge fluctuation over time. In addition, the economic growth of Iran and oil revenue have close relationship with each other. In fact, whenever oil crises happen, great fluctuation in growth rate and other indicators happened subsequently. Even though the shares of other sectors like industry and services in GDP have increased over time, the oil sector still plays a key role in the economic growth of Iran. Moreover, growth accounting analysis shows contribution of capital plays a significant role in economic growth of Iran. Furthermore, based on growth accounting framework the steady state of effective capital is 4.27 for Iran's economy.

Keywords: Growth Accounting, Growth Economics, Iran's Economy, Solow Model.

Submitted : September 10, 2021

Published : October 31, 2021

ISSN: 2507-1076

DOI: $10.24018 /$ ejbmr.2021.6.5.1099

Mohammadreza Mahmoudi

Northern Illinois University, DeKalb, IL, USA.

(e-mail: mmahmoudi@ niu.edu)

\section{INTRODUCTION}

Iran is a country in the Middle East with over 81 million inhabitants and is the world's 18 th most populous country. Also, it is the 17th largest country in the world in terms of area. Moreover, Iran has the world's second largest natural gas reserves and the fourth largest proven crude oil reserves (World Development Indicators, 2019).

In the Twentieth Century we see a great change in the economy of Iran. At the beginning of the century, Iran is an undeveloped country, while in the latter half of the 20th century the path of Iran's economic development changed dramatically [1]. During these years GDP per capita increased by about seven times. Other changes in different indicators are summarized in Table. I.

TABLE. I.CHANGE IN THE QUANTITY OF SOME INDICATORS DURING THE 20TH CENTURY

\begin{tabular}{|c|c|c|}
\hline Indicator & $\begin{array}{c}1900 \\
\text { (Rough Estimate) }\end{array}$ & 2018 \\
\hline Population (millions) & 8.6 & 80.1 \\
\hline Rank in the World & 20 & 18 \\
\hline Out of $\ldots$ & 228 & 198 \\
\hline Urban population (\% of total) & $27 \%$ & $73 \%$ \\
\hline $\begin{array}{c}\text { GDP per capita (constant } 2010 \\
\text { US\$) }\end{array}$ & $\$ 1,000$ & $\$ 6947$ \\
\hline Rank in the World & 44 & 93 \\
\hline Out of $\ldots$ & $\begin{array}{l}68 \text { countries for which } \\
\text { data is available }\end{array}$ & 184 \\
\hline $\begin{array}{c}\text { Agriculture, forestry, and fishing, } \\
\text { value added (\% of GDP) }\end{array}$ & $65 \%$ & $10 \%$ \\
\hline Life Expectancy (Total) & $<40 ?$ & 76 \\
\hline Rank in the World & $?$ & 62 \\
\hline Literacy Rate (Population 15+) & $<5 ?$ & $85 \%$ \\
\hline
\end{tabular}

Development Indicators 2018; Statistical Center of Iran.
Table I does not show the fluctuations that occurred during the 20th century, therefore Fig. 1 shows the mean and standard deviation of some critical indicators in each decade following 1960.

As described on Fig. 1, the best decade in terms of average GDP per capita is the 1970s, however, this decade had the highest value of standard deviation for GDP per capita. The highest quantity of average rate of GDP growth was reported in 1960s. In comparison, the minimum quantity of average rate of GDP growth and the maximum standard deviation of this indicator belong to the 1980s. In addition, the highest quantities of average and standard deviation of inflation were reported in the 1980s.

The main goal of this paper is to detect and explain the sources of Iranian economic growth over the contemporary era. To this end, this paper is divided into two parts. In the first part, we summarize some of the main papers' conclusions, which study economic growth using growth accounting framework. In the second part, we describe the economic growth of Iran over time. Finally, based on the growth accounting framework, the reasons behind Iran's economic growth rate are discussed.

\section{LiterATURE REVIEW}

Growth accounting is used to break down how specific factors contribute to economic growth. Estimation of various important variables and testing various propositions or alternative specifications of the growth theory are main goals of growth accounting. In fact growth accounting helps to get better understanding regarding economic growth [2]. 

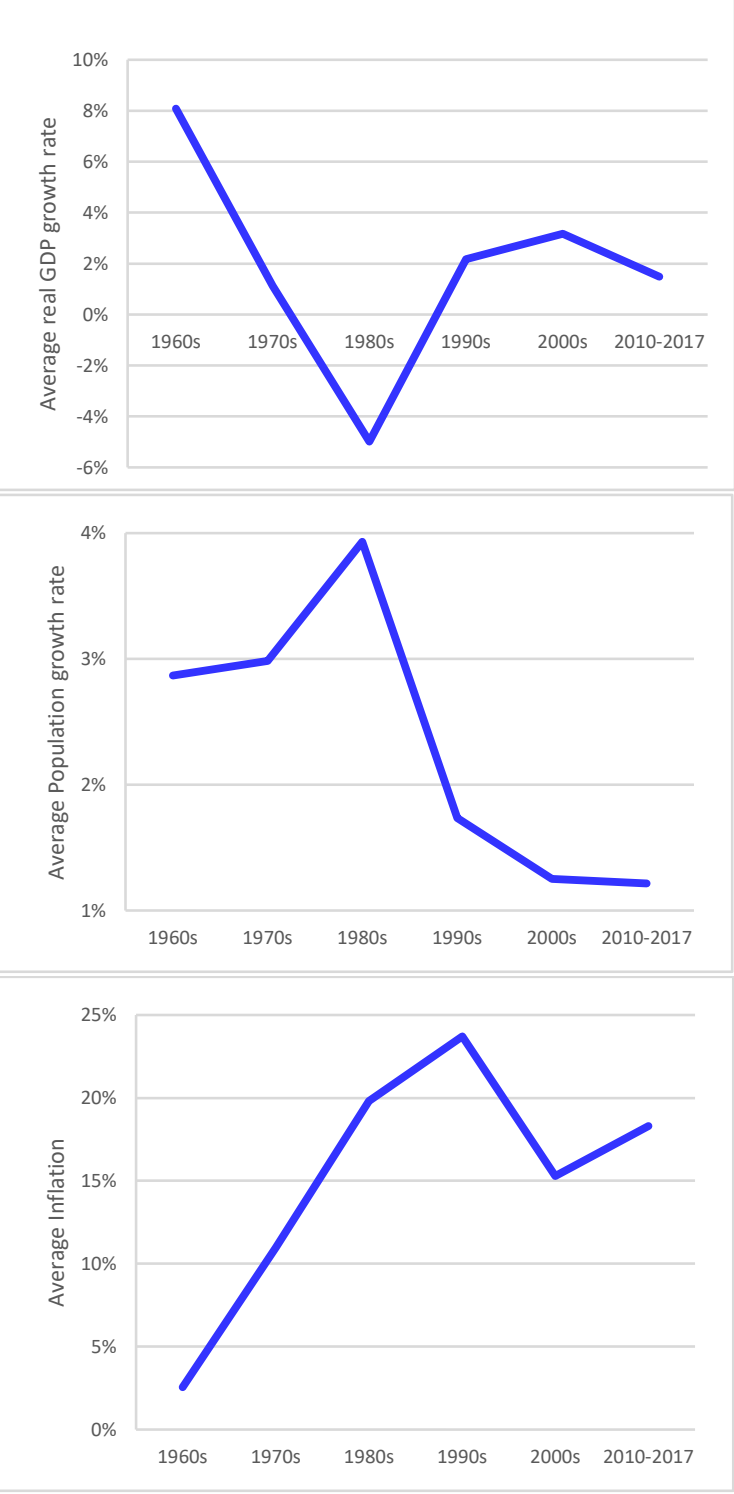
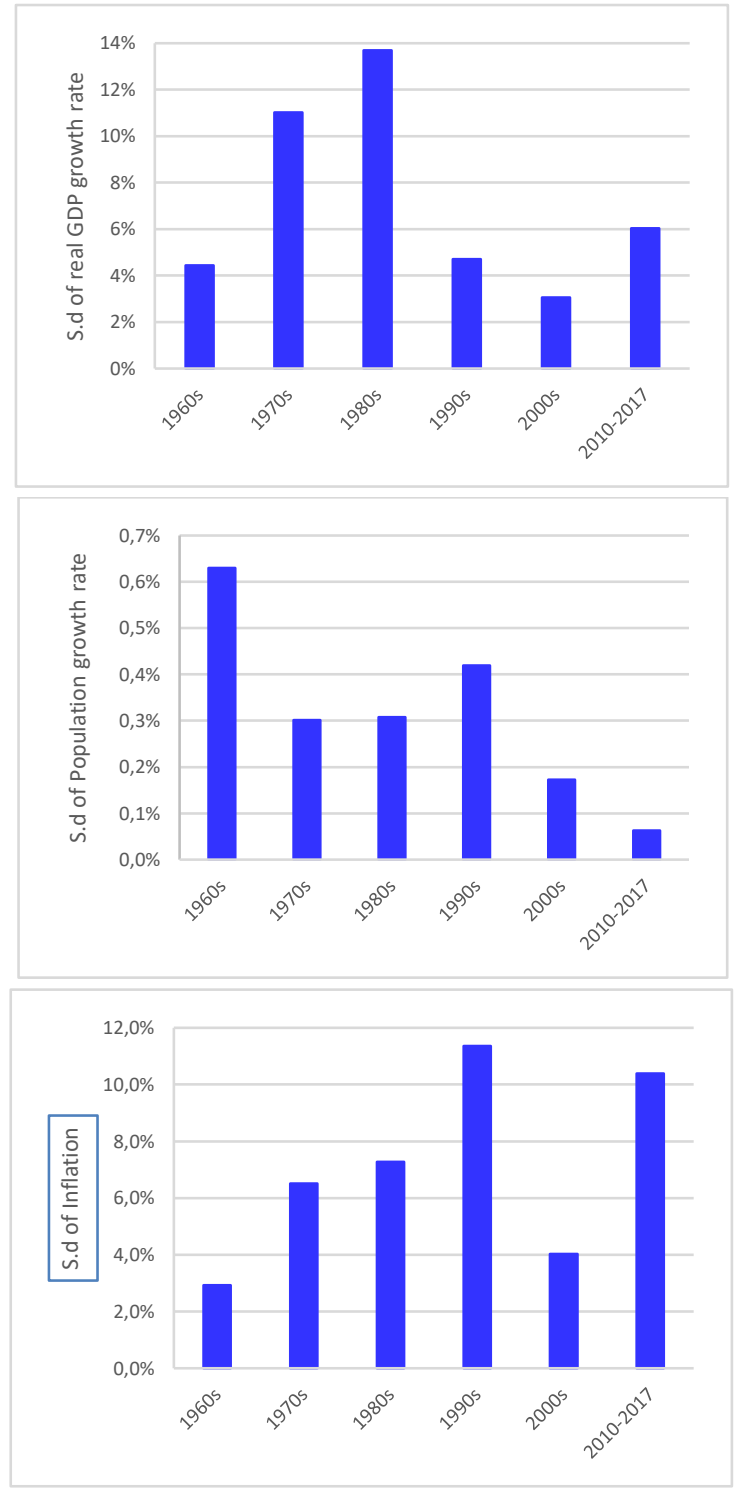

Fig. 1The statistical features of some critical indicators. Source: World Bank, World Development Indicators 2018.

[3] introduced the growth accounting approach for the first time. [4] developed this approach by emphasizing the necessity of the competitive market. The results show that the physical and human capital underestimation leads to overestimation of the contribution of technology to economic growth. Also, growth regressions, which developed by [5] become a very commonly used technique in recent years. For various studies of growth regressions, see [6], [7] and [8]. Moreover, the augmented Solow model with human capital is a generalization of the model presented in [9]. [10]emphasized the "people produce ideas" channel as a channel to generate economic growth, while [11] introduces a structural transformation from agriculture to manufacturing as an economic growth channel. [12] discussed how to correct differences in the quality of physical and human capital across countries. [13] provide an encyclopedia of the fundamental facts of economic growth based on growth theories and update the facts with the newest available data. [14] study optimal policy in the presence of several creative channels. [15] analyze the types of innovation behind US growth in recent decades using LBD data.

In addition, there are several papers which study the growth economics of Iran. [16] present a comprehensive study regarding Iran's economic growth. [1] study the economic transformation of Iran in a global context through the Twentieth Century. Their results show that Iran's economy transformed significantly during the Twentieth Century, however, the initial conditions and the evolution of domestic institutions and resources and relations with the rest of the world played critical roles in that transformation processing. [17] uses a standard measure of Total Factor Productivity (TFP) to analyze the differences between the economic performance of Iran in the two decades before and after the Islamic revolution in 1979. The results show that TFP growth rates explain 30 percent of the difference in economic performance.

\section{ANALYZING IRAN'S ECONOMIC GROWTH OVER THE CONTEMPORARY ERA}

In order to get a comprehensive picture regarding economic growth in Iran we focus on GDP per capita from 1950 to 2018. As shown in Fig. 2, GDP per capita fluctuated drastically over time, especially after the Islamic Revolution in 1979. 


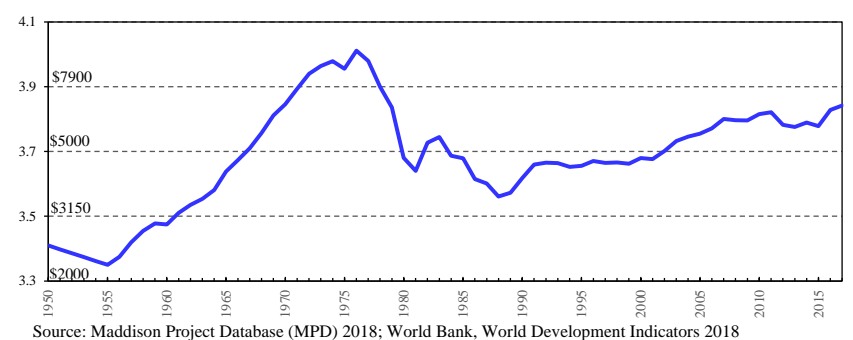

Fig. 2. GDP per person in Iran.

The maximum quantity of GDP per capita is $\$ 10,266$ which was reported in 1976 (three years after 1973 oil crisis and three years before the Islamic Revolution) and the minimum quantity is $\$ 2,238$ which was reported in 1955 (six years before the Industrialization period). Although the annual GDP per capita growth rate is around 2 percent on average, this indicator had huge fluctuations over this time. Knowing the reasons behind these variations, we split the contemporary era of Iran into several important periods and explain related economic and political situations in each period specifically.

\section{1) Period 1: 1925-1941}

Before 1950, specifically from 1925 to 1941, Reza Shah Pahlavi, the first leader of modern government in Iran, improved infrastructure profoundly. During this period, a lot of roads, hospitals, and schools were constructed so that the effect of this period on Iranian economy is inevitable [18].

\section{2) Period 2: 1961-1972}

This period is famous as the golden age of the Iranian economy, because only at these years Iran experienced strong and stable long-term economic growth. During this period, GDP per capita grew by an average annual rate of around 9 percent with the annual population growth rate of around 3 percent and average annual inflation rate of around 2 percent. As we mentioned before, infrastructure improved significantly in previous years. Moreover, due to a rise in oil revenues, the government invested a lot of money to develop oil and non-oil industries and promote manufacturing. Indeed, the role of professional economists in improving economic policies is undeniable [19], [20].

\section{3) Period 3:1972-1978}

In this period, the oil revenues reached their highest level around 1973, but the major challenge for the government was managing them properly [18]. Expansionary fiscal and monetary policy led to high and rising inflation in the mid1970s. The government's attempt to control inflation led to increase economic instability and sharp decline in investment and GDP [21]. Meantime, public dissatisfaction with economic and non-economic policies motivated a revolutionary movement that led to the Islamic Republic's establishment.

\section{4) Period 4:1978-1988}

The Islamic Revolution and the Iran-Iraq war are two very important events in the modern history of Iran, which took place during this period. In this period, the annual GDP per capita growth rate and the inflation rate were -8 percent and 19 percent, respectively. Also, population increased by 4 percent annually. These events acted a turning point and slowed the positive trend of the previous period. They also had a huge negative effect on the Iranian economy through the present day [22].

\section{A. The Relationship between Oil Revenue and Economic Growth}

Oil has been the backbone of Iranian economic development. For many years, oil earnings have provided a major part of government revenue. It is indeed the basic source of domestic investment [23]. In 1973, oil prices and government's revenue increased because of Israeli-Arab war. In addition, after the Islamic Revolution the price of oil and government revenue continued to rise, but because of the United States sanction and Iran-Iraq war the revenue of government went down. As shown in Fig. 2, value added of oil industry fluctuated significantly over time especially from 1979 to 1984, while non-oil GDP growth has had a smooth trend. The maximum quantity of the value added of oil growth rate is 128 percent, which was reported in 1982 (three years after Islamic Revolution) and the minimum quantity is -67 percent, which was reported in 1980 . Indeed, based on the data when the price of oil increased dramatically, like 1973, 1979, and 2010, value added of oil sector decreased drastically. Moreover, as it is clear in Fig. 3, GDP growth rate and value added of oil sector are highly correlated. The maximum quantity of real GDP growth rate was 23 percent, which was reported in 1982, the same year that the maximum quantity of oil's value added was reported, and the minimum quantity was -23 percent, which was reported in 1980, the same year that the minimum quantity of oil's value added was reported. It should be noted that in some years, like 1979, 1983, and 2010, the government's ability to sell oil and oil revenues decreased sharply due to the Islamic Revolution, the Iran-Iraq war and United Nations sanctions. Because of these events, we see the minimum quantity of GDP growth rate across these years. Furthermore, in 2015, after the Joint Comprehensive Plan of Action (JCPOA), the ability of the government to sell oil increased so that value added of oil went up significantly. Therefore, it can be inferred from the data that Iran's economy is highly dependent on the oil sector even in recent years. Additionally, the oil market has had significance effect on capital market of oil exporter countries like Canada, Iran, Qatar, and United Arab Emirates [24]. In addition, in order to reduce dependency of Iran's economy on oil revenue some researchers recommend expanding renewable source of energy like wave energy, wind energy, solar energy [25].

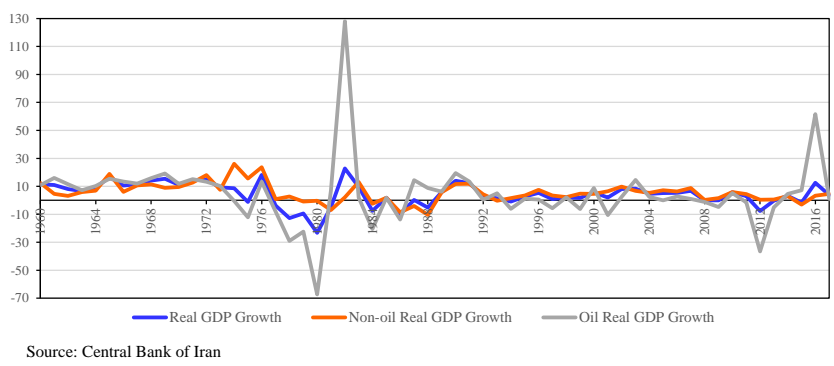

Fig. 3.Oil and Non-Oil Real GDP Growth.

\section{B. Inflation Rat}

With the exception of the 1960s, Iranian economy suffered from a high rate of inflation for many years especially after 
the Islamic Revolution [26]. Rising oil price is the main reason for the dramatic increase in inflation during 1973, 1979, 2008, and 2013, while the hyperinflation, which was reported around 1995, was associated with heavy foreign debt of government and subsequent dramatic decrease in national currency value. As it is clear in Fig. 4, inflation rate and money supply are positively correlated. When the oil price goes up the government revenue goes up. This leads to government increasing its expenditure by increasing the money supply and following this, we see great inflation rate.

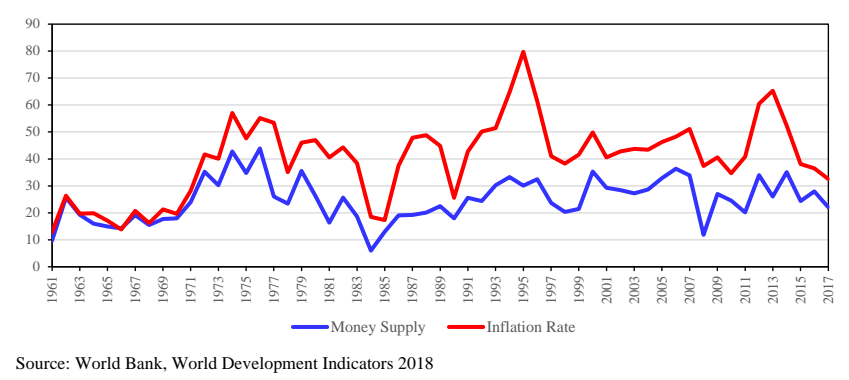

Fig. 4.Inflation and Money Supply Growth Rate.

\section{Sectoral Shares of GDP in Iran}

As described in Fig. 5, the share of oil industry decreased in recent years, even though this sector still plays a critical role in the Iranian economy. The maximum share of oil sector of GDP was reported in 1973, due to oil crisis. After the Islamic Revolution this share decreased to 15 percent, but in following years it followed a stable trend. Moreover, as shown in this figure, share of industry sector rises from 10 percent to 25 percent. Furthermore, despite the stable trend of the agriculture sector, the share of services has had great fluctuation. The share of this part increases from 30 percent to 50 percent in recent years.

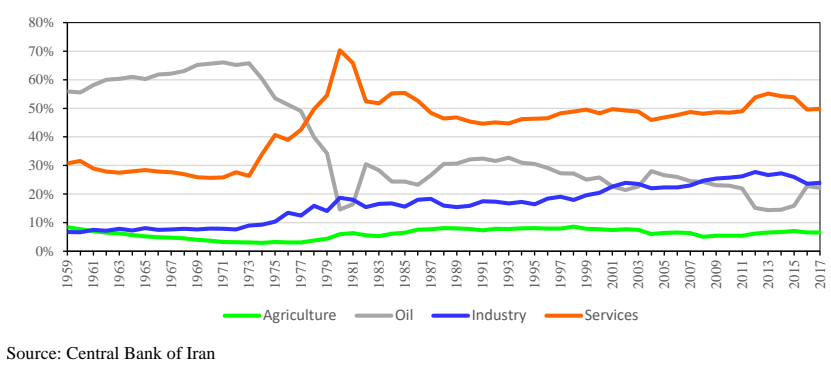

Fig. 5.The Ratio of Agriculture, Industry, Oil, and Sectors to GDP.

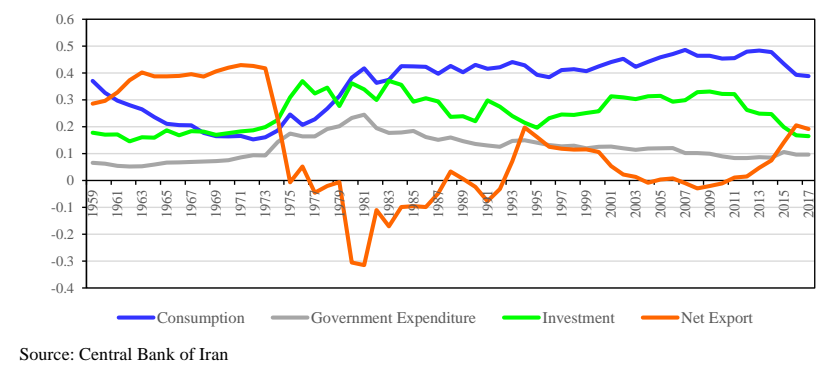

Fig. 6.Shares of Consumption, Investment, Government purchases, and Net exports to Output.

Moreover, we analyzed the ratio of different components of the expenditure side of GDP. As illustrated in Fig. 6, the share of net export has most fluctuation over time in comparison with other indicators. Especially between 1975 and 1986 because of revolution and Iran-Iraq war this index fluctuated dramatically. The share of investment fluctuated significantly, while the ratios of consumption and government expenditure have less variation.

\section{Methodology}

Growth accounting divides the growth in output of a country into two parts. The first part is the growth in output that can be attributed to growth in all factor inputs, holding technology constant. The second part is the growth that is solely due to an increase or decrease in technology. We use the following standard growth accounting framework, which was developed by [3] to analyze historical data of economic growth in Iran.

Growth accounting divides the growth in output of a country into two parts. The first part is the growth in output that can be attributed to growth in all factor inputs, holding technology constant. The second part is the growth that is solely due to an increase or decrease in technology. We use the following standard growth accounting framework, which was developed by [3] to analyze historical data of economic growth in Iran.

$$
\begin{gathered}
Y_{t}=A_{t} K_{t}^{\alpha} L_{t}^{1-\alpha} \\
\log \left(\frac{Y_{t+1}}{Y_{t}}\right)=\log \left(\frac{A_{t+1}}{A_{t}}\right)+\alpha \log \left(\frac{K_{t+1}}{K_{t}}\right)+(1- \\
\alpha) \log \left(\frac{L_{t+1}}{L_{t}}\right)
\end{gathered}
$$

where Y, K, L, and A are output, capital stock, labor force and total factor productivity (TFP) which estimated as residual. Additionally, $\alpha$ represents the capital share. Based on The Penn World Table (version 9.0) data, the average share of labor for the Iranian economy is about 66 percent. Then, we calculate the share of capital easily by (1- Share of Labor), which equals to 34 percent. By multiplying these numbers by the capital and labor growth rate we compute contributions of capital and labor. Moreover, by subtracting the GDP growth rate from both capital and labor contributions we compute the contribution of technology. As seen in the TABLE II, from 1960 to 2018, GDP grew by 94 percent; the contributions of capital, labor, and productivity are 33, 46, and 14 percent, respectively. However, each decade has different growth rate and contributions of labor, capital, and technology.

TABLE II: GROWTH ACCOUNTING FOR IRAN

\begin{tabular}{ccccc}
\hline \hline Period & $\begin{array}{c}\text { Growth } \\
\text { Rate }\end{array}$ & $\begin{array}{c}\text { Contribution } \\
\text { of Capital }\end{array}$ & $\begin{array}{c}\text { Contribution } \\
\text { of Labor }\end{array}$ & $\begin{array}{c}\text { Contribution } \\
\text { of TFP }\end{array}$ \\
\hline $1960-2018$ & 0.94 & 0.33 & 0.46 & 0.14 \\
$1960-1969$ & 0.44 & 0.15 & 0.06 & 0.23 \\
$1970-1979$ & 0.11 & 0.10 & 0.08 & -0.08 \\
$1980-1989$ & 0.04 & -0.09 & 0.09 & 0.04 \\
$1990-1999$ & 0.11 & 0.00 & 0.09 & 0.02 \\
$2000-2009$ & 0.16 & 0.11 & 0.08 & -0.03 \\
$2010-2018$ & 0.06 & -0.03 & 0.02 & 0.08 \\
\hline \hline
\end{tabular}

Source: The Penn World Table (version 9.0); World Bank, World Development Indicators 2018.

Furthermore, as it is clear in Fig. 7, contribution of capital plays a significant role in economic growth of Iran. Including 
the decades in which Iranian economy experienced depression for several years, the contribution of technology was significantly low. On the other hand, when the Iranian economy has growth for several years, the contribution of productivity is significantly high. These results are likely due to our estimation of total factor productivity as residual.

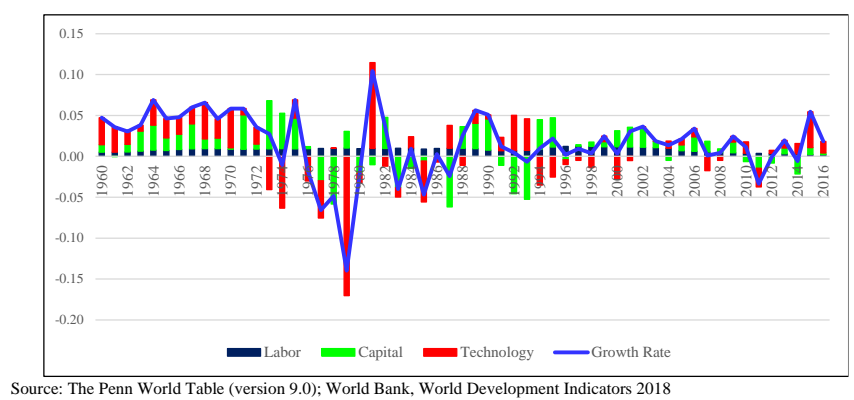

Fig. 7.Growth Accounting for Iran.

\section{A. Analyzing the Steady State of Capital for Iranian Economy}

In this section we compute the steady state of capital and analyze Iran's economy around the steady state based on the following model.

$$
\sum_{t=0}^{\infty} \beta^{t} \frac{C_{t}^{1-\gamma}}{1-\gamma}
$$

s.t

$$
\begin{aligned}
& Y_{t}=A_{t} K_{t}^{\alpha}\left(l_{t}\right)^{1-\alpha} \\
& C_{t}+I_{t}=Y_{t} \\
& K_{t+1}=(1-\delta) K_{t}+I_{t} \\
& C_{t}, K_{t+1} \geq 0
\end{aligned}
$$

In above system, $A_{0}>0, K_{0}>0$, and $L_{0}>0$ are given for all t. At time t, $C_{t}$ is consumption, $Y_{t}$ is output, $A_{t}$ is productivity, $K_{t}$ is physical capital, $L_{t}$ is labor, and $I_{t}$ is investment. The discount rate, $\beta$, satisfies $0<\beta<1$. The capital share, $\alpha$, satisfies $0<\alpha<1$. The depreciation rate of capital, $\delta$, satisfies $0<\delta<1$. Relative risk-aversion, $\gamma$, satisfies $\gamma>0$ and $\gamma \neq 1$. We assume that productivity grows at the constant rate a and that labor grows at the constant rate $\mathrm{n}$.

Since productivity and labor growing at the constant rate, there is no steady state for above system. One way to resolve this issue is as follows;

We write production function like following equation:

$$
Y_{t}=K_{t}^{\alpha}\left(A_{t}^{\frac{1}{1-\alpha}} L_{t}\right)^{1-\alpha}(8)
$$

By dividing both sides of equation 8 by $\left(A_{t}^{\frac{1}{1-\alpha}} L_{t}\right)$ we get equation (9).

$$
y_{t}=k_{t}^{\alpha}
$$

where $y_{t}=\left(\frac{Y_{t}}{A_{t}^{\frac{1}{1-\alpha}} L_{t}}\right)$ is output for effective labor, and $k_{t}=$ $\left(\frac{K_{t}}{A_{t}^{\frac{1}{1-\alpha}} L_{t}}\right)$ is capital for effective labor.

We write the same process for other equations.

By Dividing both sides of equation 5 by $\left(A_{t}^{\frac{1}{1-\alpha}} L_{t}\right)$ we have:

$$
c_{t}+i_{t}=y_{t}
$$

where $c_{t}=\left(\frac{C_{t}}{A_{t}^{\frac{1}{1-\alpha}} L_{t}}\right)$, and $i_{t}=\left(\frac{I_{t}}{A_{t}^{\frac{1}{1-\alpha}} L_{t}}\right)$.

$i_{t}=k_{t+1}-(1-\delta) k_{t}$

Then, we write control variable as a function of state variable:

$$
c_{t}=k_{t}^{\alpha}-k_{t+1}+(1-\delta) k_{t}
$$

Now, this model has steady state, and we write objective function as follows:

$$
\sum_{t=0}^{\infty} \beta^{t} \frac{\left(k_{t}^{\alpha}-k_{t+1}+(1-\delta) k_{t}\right)^{1-\gamma}}{1-\gamma}
$$

We want to find derivative with respect to $k_{t+1} \cdot k_{t+1}$ appears in two periods $t$ and $t+1$, so that the derivative of objective function with respect to $k_{t+1}$ is calculated as follows:

$$
\begin{aligned}
& \ldots \quad \beta^{t} \frac{\left(k_{t}^{\alpha}-k_{t+1}+(1-\delta) k_{t}\right)^{1-\gamma}}{1-\gamma} \\
& \beta^{t+1} \frac{\left(k_{t+1}^{\alpha}-k_{t+2}+(1-\delta) k_{t+1}\right)^{1-\gamma}}{1-\gamma}+\ldots \\
& \text { F.O.C w.r.t } k_{t+1}: \\
& \quad-\beta^{t}\left(k_{t}^{\alpha}-k_{t+1}+(1-\delta) k_{t}\right)^{-\gamma}+ \\
& +\beta^{t+1}\left(k_{t+1}^{\alpha}-k_{t+2}+(1-\delta) k_{t+1}\right)^{-\gamma}\left(\alpha k_{t+1}^{\alpha-1}+(1-\right. \\
& \delta))=0
\end{aligned}
$$

By Dividing equation 15 by $\beta^{t}$ we get equation (14).

$$
\left(c_{t}\right)^{-\gamma}=\beta\left(c_{t+1}\right)^{-\gamma}\left(\alpha k_{t+1}^{\alpha-1}+(1-\delta)\right)
$$

At balance growth path $\frac{c_{t+1}}{c_{t}}=\frac{y_{t+1}}{y_{t}}=1+g$, also at the steady state we have $\bar{k}$, then we write equation 16 as follows:

$$
\begin{aligned}
& \left(\frac{c_{t+1}}{c_{t}}\right)^{\gamma}=\beta\left(\alpha \bar{k}^{\alpha-1}+(1-\delta)\right) \\
& (1+g)^{\gamma}=\beta\left(\alpha \bar{k}^{\alpha-1}+(1-\delta)\right) \\
& \frac{(1+g)^{\gamma}-\beta(1-\delta)}{\alpha \beta}=\bar{k}^{\alpha-1}
\end{aligned}
$$

Therefore, the steady state of effective capital per person is equal to:

$$
\bar{k}=\left(\frac{\alpha \beta}{(1+g)^{\gamma}-\beta(1-\delta)}\right)^{\frac{1}{1-\alpha}}
$$


Moreover, we calculate $(1+\mathrm{g})$ using production function as follows:

$$
\begin{aligned}
& Y_{t}=A_{t} K_{t}^{\alpha}\left(L_{t}\right)^{1-\alpha} \\
& \frac{Y_{t+1}}{Y_{t}}=\left(\frac{A_{t+1}}{A_{t}}\right)\left(\frac{K_{t+1}}{K_{t}}\right)^{\alpha}\left(\frac{L_{t+1}}{L_{t}}\right)^{1-\alpha}
\end{aligned}
$$

By considering balance growth path relations and the growth rate of labor and productivity, we write equation 22 as follows:

$$
\begin{aligned}
& (1+g)=(1+a)(1+n)^{1-\alpha}(1+g)^{\alpha} \\
& (1+g)^{1-\alpha}=(1+a)(1+n)^{1-\alpha} \\
& (1+g)=(1+a)^{\frac{1}{1-\alpha}}(1+n)
\end{aligned}
$$

We write objective function and balance growth path again for calculating $\frac{K_{t}}{Y_{t}}$, and $\frac{I_{t}}{Y_{t}}$.

$$
C_{t}=A_{t} K_{t}^{\alpha} L_{t}^{1-\alpha}-K_{t+1}+(1-\delta) K_{t}
$$

The derivative of objective function with respect to $k_{t+1}$ is as follows:

$$
\begin{gathered}
\ldots+\beta^{t} \frac{\left(A_{t} K_{t}^{\alpha} L_{t}^{1-\alpha}-K_{t+1}+(1-\delta) K_{t}\right)^{1-\gamma}}{1-\gamma} \\
\beta^{t+1} \frac{\left(A_{t+1} K_{t+1}^{\alpha} L_{t+1}^{1-\alpha}-K_{t+2}+(1-\delta) K_{t+1}\right)^{1-\gamma}}{1-\gamma}+\ldots
\end{gathered}
$$

F.O.C w.r.t $K_{t+1}$ :

$$
\left(C_{t}\right)^{-\gamma}=\beta\left(C_{t+1}\right)^{-\gamma}\left(\alpha A_{t+1} K_{t+1}^{\alpha} L_{t+1}^{1-\alpha}+(1-\delta)\right)
$$

where, $A_{t+1} K_{t+1}^{\alpha} L_{t+1}^{1-\alpha}=\frac{Y_{t+1}}{K_{t+1}}$, and based on balance growth path $\frac{C_{t+1}}{C}=\frac{Y_{t+1}}{Y_{t}}=\frac{K_{t+1}}{K_{t}}=1+g$.

Hence, we write equation 28 as follows:

$$
\begin{aligned}
& (1+g)^{\gamma}=\beta\left(\alpha \frac{Y_{t+1}}{K_{t+1}}+(1-\delta)\right) \\
& \frac{(1+g)^{\gamma}-\beta(1-\delta)}{\alpha \beta}=\frac{Y_{t+1}}{K_{t+1}}
\end{aligned}
$$

$\frac{K_{t+1}}{Y_{t+1}}=\frac{\alpha \beta}{(1+g)^{\gamma}-\beta(1-\delta)}$

Therefore, we compute $\frac{K_{t}}{Y_{t}}$ as follows:

$\frac{K_{t+1}}{Y_{t+1}} \frac{Y_{t+1}}{K_{t+1}} \frac{K_{t}}{Y_{t}}=\frac{\alpha \beta}{(1+g)^{\gamma}-\beta(1-\delta)} \frac{Y_{t+1}}{K_{t+1}} \frac{K_{t}}{Y_{t}}$

$\frac{K_{t}}{Y_{t}}=\frac{\alpha \beta}{(1+g)^{\gamma}-\beta(1-\delta)}$

Also, we do the following process for computing $\frac{I_{t}}{Y_{t}}$.

$$
\begin{aligned}
& I_{t}=K_{t+1}-(1-\delta) K_{t} \\
& \frac{I_{t}}{Y_{t}}=\frac{K_{t+1}}{Y_{t}}-(1-\delta) \frac{K_{t}}{Y_{t}}
\end{aligned}
$$

To compute $\frac{K_{t+1}}{Y_{t}}$, we use equation 31 and rewrite it as follows:

$$
\begin{aligned}
& \frac{K_{t+1}}{Y_{t+1}} \frac{Y_{t+1}}{Y_{t}}=\frac{\alpha \beta}{(1+g)^{\gamma}-\beta(1-\delta)} \frac{Y_{t+1}}{Y_{t}} \\
& \frac{K_{t+1}}{Y_{t}}=\frac{\alpha \beta}{(1+g)^{\gamma}-\beta(1-\delta)}(1+g)
\end{aligned}
$$

Therefore, $\frac{I_{t}}{Y_{t}}$ equals to:

$$
\begin{aligned}
& \frac{I_{t}}{Y_{t}}=\frac{\alpha \beta}{(1+g)^{\gamma}-\beta(1-\delta)}(1+g)-(1-\delta) \frac{\alpha \beta}{(1+g)^{\gamma}-\beta(1-\delta)}= \\
& \frac{\alpha \beta}{(1+g)^{\gamma}-\beta(1-\delta)}(g+\delta)
\end{aligned}
$$

We compute different formula that enable us to calculate parameters, and steady state. In following, the process of calibrating parameters for Iranian economy is explained step by step.

In the first step, we define steady state period. Based on the data, the performance of the Iranian economy between 1996 to 2005 satisfies the steady state condition. During this period the government was politically stabilized and it did not face with any significant internal or external challenges. Moreover, as it is clear in Fig. 8, during this period output and consumption were likely growing at the same rate, which means $\frac{Y_{t+1}}{Y_{t}}=\frac{C_{t+1}}{C_{t}}=1+\mathrm{g}$.

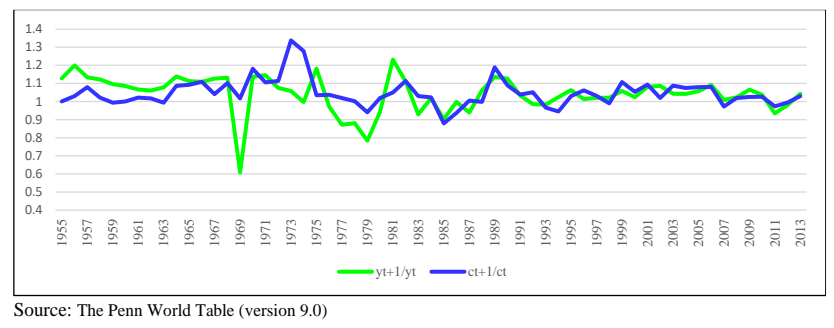

Fig. 8.Growth Rate of Output and Consumption.

In the second step, we calibrate the parameters for this period as follows.

- Based on the Penn World Table (version 9.0) data, the average capital share of Iran's economy, $\alpha$, is 34 percent. Also, growth rate of productivity, a, and growth rate of labor, $\mathrm{n}$, are .04 percent and 2 percent, respectively. By plugging the quantities of $\mathrm{n}$ and a into the equation 25 we calculate $(1+\mathrm{g})$, which equals to 1.02 .

- Based on The Penn World Table (version 9.0) data, the average depreciation rate of capital for Iran's economy is 5 percent.

- For calibrating other parameters, $\beta$ and $\gamma$, we use the following procedure:

- First, we calculate the average of $\frac{I_{t}}{Y_{t}}$ for the steady state period. This term equals to 0.21 .

- By Plugging the quantities for parameters in equation 25 , we have the following formula that show us the relation between $\beta$ and $\gamma$.

$$
0.21=\frac{0.33 \beta}{(1.02)^{\gamma}-\beta(0.95)}(0.07)
$$


- Second, we calculate the average of $\frac{K_{t}}{Y_{t}}$ for the steady state period. This term equals to 2.63 .

- By Plugging the quantities for parameters in equation 25 , we have another formula that show us the relation between $\beta$ and $\gamma$.

$$
2.63=\frac{0.33 \beta}{(1.02)^{\gamma}-\beta(0.95)}
$$

- Third, we put different quantities of $\beta$ and $\gamma$ in above equations and choose the ones that match the steady state values of $\frac{I_{t}}{Y_{t}}$ and $\frac{K_{t}}{Y_{t}}$ to real data. We do the matching process through 3 scenarios. As it is clear in TABLE III, the best quantities of $\beta$ and $\gamma$ which give us the closest quantities of $\frac{K_{t}}{Y_{t}}$ and $\frac{I_{t}}{Y_{t}}$ to the real data are 0.93 and 0.4 , respectively.

- Finally, by plugging the quantities of different parameters into the equation 20 we compute steady state of effective capital, which is 4.27 for Iran's economy.

\begin{tabular}{lcccccc}
\multicolumn{6}{c}{ TABLE III: CALIBRATING THE PARAMETERS } \\
\hline \hline & $\beta$ & $\gamma$ & $\frac{K_{t}}{Y_{t}}$ & & $\frac{I_{t}}{Y_{t}}$ & $\bar{k}$ \\
\hline Scenario 1 & 0.97 & 1.8 & 2.78 & 0.20 & 4.72 \\
Scenario 2 & 0.94 & 0.20 & 2.8 & 0.20 & 4.8 \\
Scenario 3 & 0.93 & 0.4 & 2.61 & 0.201 & 4.27 \\
\hline \hline
\end{tabular}

Source: Researcher Computations.

\section{CONCLUSION}

Although GDP per capital increased by 2 percent annually from 1950 to 2018, this indicator has had a huge fluctuation over time. Before the Islamic Revolution Iran experienced high rate of economic growth and low rate of inflation especially from 1961 to 1971 . However, after the Islamic Revolution we see a great fluctuation in growth rate and high level of inflation rate. Historical data shows a close relationship between economic growth of Iran and oil revenue. Even though the shares of other sectors like industry and services in GDP have increased over the time, oil sector still plays a key role in economic growth of Iran. Furthermore, growth accounting framework shows contribution of capital affects Iranian economic growth rate significantly and the steady state of effective capital is 4.27 for Iran's economy.

\section{REFERENCES}

[1] Esfahani HS, Pesaran H. Iranian Economy in the 20th Century: A Global Perspective. CWPE. 2008;815:1-37.

[2] Acemoglu D. Introduction to modern economic growth. Privredna kretanja i ekonomska politika. 2010;123:89.

[3] Solow RM. Technical change and the aggregate production function. The review of Economics and Statistics. 1957:312-20.

[4] Gollop FM, Fraumeni BM, Jorgenson DW. Productivity and US economic growth. 1987.

[5] Barro RJ. Economic growth in a cross section of countries. The quarterly journal of economics. 1991;106(2):407-43.

[6] Durlauf SN. A theory of persistent income inequality. Journal of Economic growth. 1996;1(1):75-93.
[7] Durlauf SN, Johnson PA, Temple JR. Growth econometrics. Handbook of economic growth. 2005;1:555-677.

[8] Wooldridge JM. Econometric analysis of cross section and panel data MIT press. Cambridge, MA. 2002;108.

[9] Mankiw NG, Romer D, Weil DN. A contribution to the empirics of economic growth. The quarterly journal of economics. 1992;107(2):407-37.

[10] Jones CI. Was an industrial revolution inevitable? Economic growth over the very long run. Advances in macroeconomics. 2001;1(2).

[11] Hansen GD, Prescott EC. Malthus to solow. American economic review. 2002;92(4):1205-17.

[12] Caselli F. Accounting for cross-country income differences. Handbook of economic growth. 2005;1:679-741.

[13] Jones CI. The facts of economic growth. Handbook of macroeconomics. 2: Elsevier; 2016. p. 3-69.

[14] Atkeson A, Burstein AT, Chatzikonstantinou M. Transitional Dynamics in Aggregate Models of Innovative Investment. Annual Review of Economics. 2019;11:273-301.

[15] Garcia-Macia D, Hsieh CT, Klenow PJ. How destructive is innovation? Econometrica. 2019;87(5):1507-41.

[16] Jbili A, Kramarenko V, Bailén J. Islamic Republic of Iran-Selected Issues: International Monetary Fund; 2004.

[17] Mojaver F. Sources of economic growth and stagnation in Iran. The Journal of International Trade \& Economic Development. 2009;18(2):275-95.

[18] Pesaran MH. The role of economic theory in modelling the long run. The economic journal. 1997;107(440):178-91.

[19] Esfahani HS, Pesaran MH. The Iranian economy in the twentieth century: A global perspective. Iranian Studies. 2009;42(2):177-211.

[20] Esfahani HS, Squire L. Explaining trade policy in the Middle East and North Africa. The Quarterly Review of Economics and Finance. 2007;46(5):660-84.

[21] Katouzian H. Ideology and method in economics: Macmillan International Higher Education; 1980.

[22] Acemoglu D, Robinson JA. Why nations fail: The origins of power, prosperity, and poverty: Currency; 2012.

[23] Pesaran MH. Economic trends and macroeconomic policies in postrevolutionary Iran: University of Cambridge, Department of Applied Economics Cambridge; 1998.

[24] Mahmoudi M, Ghaneei H. Detection of Structural Regimes and Analyzing the Impact of Crude Oil Market on Canadian Stock Market: Markov Regime-Switching Approach. arXiv preprint arXiv:210901046. 2021.

[25] Ghaneei H, Mahmoudi M. Simulation, Optimization and Economic Assessment of Pelamis Wave Energy Converter. Available at SSRN 3939656. 2021.

[26] Liu O, Adedeji O. Determinants of inflation in the Islamic Republic of Iran: A macroeconomic analysis. 2000. 